Supporting Information 


\section{Sodium cobalticarborane: A promising precatalyst for oxygen- evolution reaction}

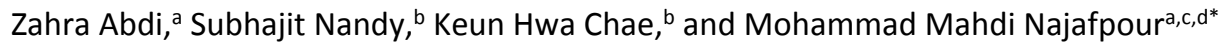

aDepartment of Chemistry, Institute for Advanced Studies in Basic Sciences (IASBS), Zanjan, 45137-66731, Iran

${ }^{b}$ Advanced Analysis Center, Korea Institute of Science and Technology, Seoul 02792, Republic of Korea

${ }^{c}$ Center of Climate Change and Global Warming, Institute for Advanced Studies in Basic Sciences (IASBS), Zanjan,

45137-66731, Iran

${ }^{\mathrm{d}}$ Research Center for Basic Sciences \& Modern Technologies (RBST), Institute for Advanced Studies in Basic

Sciences (IASBS), Zanjan 45137-66731, Iran

*Corresponding author; E-mail: mmnajafpour@iasbs.ac.ir (MMN) 
Table of contents

\begin{tabular}{|c|c|}
\hline Title & Page \\
\hline Experimental Section & S4, S5 \\
\hline Scheme S1 The setup for the electrochemical experiment & S6 \\
\hline Figure S1 SEM images of a bare FTO electrode & S7 \\
\hline $\begin{array}{l}\text { Figure S2 SEM images of an FTO in the presence of } 1(1.4 \mathrm{mM}) \text { under chronoamperometry at } 2.36 \\
V \text { for two }(a-c) \text {, four (d-f), and } 24 \text { hours }(\mathrm{g}-\mathrm{j}) \text { in a } \mathrm{KOH} \text { solution }(1.0 \mathrm{M})\end{array}$ & S8 \\
\hline $\begin{array}{l}\text { Figure S3 SEM images of an FTO in the presence of } 1(1.4 \mathrm{mM}) \text { under chronoamperometry at } 2.36 \\
V \text { for two hours }\end{array}$ & S9 \\
\hline $\begin{array}{l}\text { Figure S4 EDX-Mapping of an FTO in the presence of } \mathbf{1}(1.4 \mathrm{mM}) \text { under chronoamperometry at } \\
2.36 \mathrm{~V} \text { for two hours }\end{array}$ & S10 \\
\hline $\begin{array}{l}\text { Figure S5 EDX spectra of an FTO in the presence of } 1(1.4 \mathrm{mM}) \text { under chronoamperometry at } 2.36 \\
\vee \text { for two hours }\end{array}$ & S11 \\
\hline $\begin{array}{l}\text { Figure S6 SEM images of an FTO in the presence of } \mathbf{1}(1.4 \mathrm{mM}) \text { under chronoamperometry at } 2.36 \\
V \text { for four hours }\end{array}$ & S12 \\
\hline $\begin{array}{l}\text { Figure S7 EDX-Mapping of an FTO in the presence of } \mathbf{1}(1.4 \mathrm{mM}) \text { under chronoamperometry at } \\
2.36 \mathrm{~V} \text { for four hours }\end{array}$ & S13 \\
\hline $\begin{array}{l}\text { Figure S8 EDX spectra of an FTO in the presence of } 1(1.4 \mathrm{mM}) \text { under chronoamperometry at } 2.36 \\
V \text { for four hours }\end{array}$ & S14 \\
\hline $\begin{array}{l}\text { Figure S9 SEM images of an FTO in the presence of } \mathbf{1}(1.4 \mathrm{mM}) \text { under chronoamperometry at } 2.36 \\
V \text { for } 24 \text { hours }\end{array}$ & S15 \\
\hline $\begin{array}{l}\text { Figure S10 EDX-Mapping of an FTO in the presence of } 1(1.4 \mathrm{mM}) \text { under chronoamperometry at } \\
2.36 \mathrm{~V} \text { for } 24 \text { hours }\end{array}$ & S16 \\
\hline $\begin{array}{l}\text { Figure S11 EDX spectra of an FTO in the presence of } 1(1.4 \mathrm{mM}) \text { under chronoamperometry at } \\
2.36 \mathrm{~V} \text { for } 2 \text { 24hours }\end{array}$ & S17 \\
\hline $\begin{array}{l}\text { Figure S12 SEM-EDX mapping (Co: purple; B: green) of } 1 \text { under the chronoamperometry at } 2.36 \\
\vee \text { for two (a-c), four (d-f), and } 24 \text { hours (g-i) in a } \mathrm{KOH} \text { solution }(1.0 \mathrm{M}) \text {. }\end{array}$ & S18 \\
\hline $\begin{array}{l}\text { Figure } \mathrm{S} 13 \mathrm{CV} \text { with different scan rates in pure acetonitrile }\left(\mathrm{LiClO}_{4}: 0.25 \mathrm{M}\right) \text { in the } \\
\text { presence of } \mathbf{1}(1.4 \mathrm{mM}) \text { using FTO }\end{array}$ & S19 \\
\hline $\begin{array}{l}\text { Figure S14 LSVs of an FTO in the presence and the absence of } 1(1.4 \mathrm{mM}) \text { in the } \mathrm{KOH} \\
\text { solution }(1.0 \mathrm{M}) \text { at different scan rates }\end{array}$ & S20 \\
\hline $\begin{array}{l}\text { Figure S15 LSVs of an FTO in the presence and the absence of } 1(1.4 \mathrm{mM}) \text { in the } \mathrm{KOH} \\
\text { solution }(1.0 \mathrm{M}) \text { at different scan rates }\end{array}$ & S21 \\
\hline $\begin{array}{l}\text { Figure S16 SEM images show no nanosized particle containing cobalt after washing with EDTA at } \\
\text { different magnifications (a-c) }\end{array}$ & S22 \\
\hline $\begin{array}{l}\text { Figure S17 SEM-EDX mapping shows no nanosized particle containing cobalt after washing with } \\
\text { EDTA }\end{array}$ & S23 \\
\hline Figure S18 EDX spectra show traces of cobalt after washing with EDTA & S24 \\
\hline $\begin{array}{l}\text { Figure. S19 LSVs of Pt (blue), Au (orange), and GC (gray) in the presence of } \mathrm{KOH}(1.0 \mathrm{M}) \text { and in } \\
\text { the absence of } 1\end{array}$ & S25 \\
\hline $\begin{array}{l}\text { Figure S20 CVs of Pt (blue), Au (orange), and GC (gray) in the presence of } \mathrm{KOH}(1.0 \mathrm{M}) \text { and in the } \\
\text { absence of } 1\end{array}$ & S26 \\
\hline $\begin{array}{l}\text { Figure S21 SEM images of an FTO in the presence of } 1(1.4 \mathrm{mM}) \text { under chronoamperometry at } \\
2.36 \mathrm{~V} \text { for two hours in the } \mathrm{KOH} \text { solution }(1.0 \mathrm{M}) \text { at different magnifications for } \mathrm{Au}(\mathrm{a} \text { and } \mathrm{b}), \mathrm{Pt} \\
(\mathrm{c} \text { and } \mathrm{d}) \text {, and } \mathrm{C} \text { ( } \mathrm{e} \text { and } \mathrm{f} \text { ) as working electrode. }\end{array}$ & S27 \\
\hline Reference & S28 \\
\hline
\end{tabular}




\section{Experimental}

\section{Materials}

All reagents and solvents were purchased from commercial sources and used without further purifications. Sodium cobalticarborane was purchased from Alfa Chemistry Company. Fluorine-doped tin oxide coated glass slide electrode (FTO; surface resistivity $\sim 7 / \mathrm{sq}$ ) was purchased from the Sigma-Aldrich Company.

\section{Characterizations}

Scanning electron microscopy (SEM)

LEO 1430VP

\section{High-resolution transmission electron microscopy (HRTEM) and TEM analyses}

Philips CM120 electron microscopy.

\section{EDX analysis/mapping}

The scanning electron microscope CamScan 4DV (CamScan UK)

\section{X-ray powder diffraction patterns}

Bruker, D8 ADVANCE (Germany) diffractometer (Cu- $\mathrm{K}_{\alpha}$ radiation)

\section{X-ray photoelectron spectroscopy}

All spectra were collected using K-ALPHA, Thermo Scientific (Al- $\mathrm{K}_{\alpha}$ radiation (1486.6 eV)) monochromatized by a twin crystal monochromator, yielding a focused X-ray spot at $3 \mathrm{~mA} \times 12 \mathrm{kV}$. The alpha hemispherical analyzer was operated in the constant energy mode with survey scan pass energies of $200 \mathrm{eV}$ to measure the whole energy band and $50 \mathrm{eV}$ in a narrow scan to selectively measure the particular elements. XPS data were analyzed with Avantage software.

\section{X-ray absorption spectroscopy}

The extended X-ray absorption fine structure (EXAFS) measurements for solid material formed on the surface of electrode after OER and references ( $\mathrm{Co}$ metal, $\mathrm{CoO}$, and $\mathrm{CO}_{2} \mathrm{O}_{3}$ ) were performed at the $1 D$ XAS KIST-PAL beamline at Pohang Light Source (PLS), operating at $3.0 \mathrm{GeV}$ with a storage current of $250 \mathrm{~mA}$ top-up mode. The beamline is a bending magnet X-ray scattering (XRS) beamline which uses a Si(111) double crystal monochromator to give a wide 
range of monochromatic energies (4 - $16 \mathrm{keV})$. Higher harmonics were removed by detuning the incident beam intensity to $60 \%$ of the maximum intensity. Three ionization chambers filled with $\mathrm{He}$ and $\mathrm{N}_{2}$ gases were used to record the intensity of the incident and the transmitted X-rays, respectively. These materials are placed between the first and second ionization chamber, while reference foil (Co) for energy calibration is placed between the second and the third ionization chamber. Under stationary conditions, extended X-ray absorption fine-structure (EXAFS) measurements were performed around the Co K-edge in the step scanning mode. The obtained data are processed by using ATHENA. ${ }^{1}$

\section{Electrochemical experiments}

EmStat3+ from PalmSens (Netherlands) (Scheme S1). Chronoamperometry, LSV, and CV were performed from low to high potential. A three-electrode set-up was used with an $\mathrm{Hg} / \mathrm{HgO}$, a Pt foil, and GC $\left(\left(0.0314 \mathrm{~cm}^{2}\right), \mathrm{FTO}\left(1.0 \mathrm{~cm}^{2}\right)\right.$, Pt $\left(0.0314 \mathrm{~cm}^{2}\right)$, or $\mathrm{Au}\left(0.0314 \mathrm{~cm}^{2}\right)$ as the reference, counter and working electrodes, respectively. To convert the measured potential to RHE, it is determined by cyclic voltammetry (CV) in the range of hydrogen evolution/oxidation at a Pt electrode in $\mathrm{H}_{2}$-saturated electrolyte, using a $\mathrm{H}_{2}$ generation, with the scan rate of $10 \mathrm{mV} / \mathrm{s}$ under stirrer at zero current.

\section{Oxygen evolution reactions}

measured with a HQ40d portable dissolved oxygen-meter connected to an oxygen monitor with a digital readout at $25^{\circ} \mathrm{C}$. The measurement was first done with an air-saturated water to calibrate the oxygen meter.

\section{Raman spectra}

XploRA ONE ${ }^{\mathrm{TM}}$ Raman Microscope from Horiba Company using $532 \mathrm{~nm}$ laser. The devolution plots were calculated by Origin software using Gauss function. The Raman spectra were performed by the software " LabSpec 6 from" from Horiba Company. 


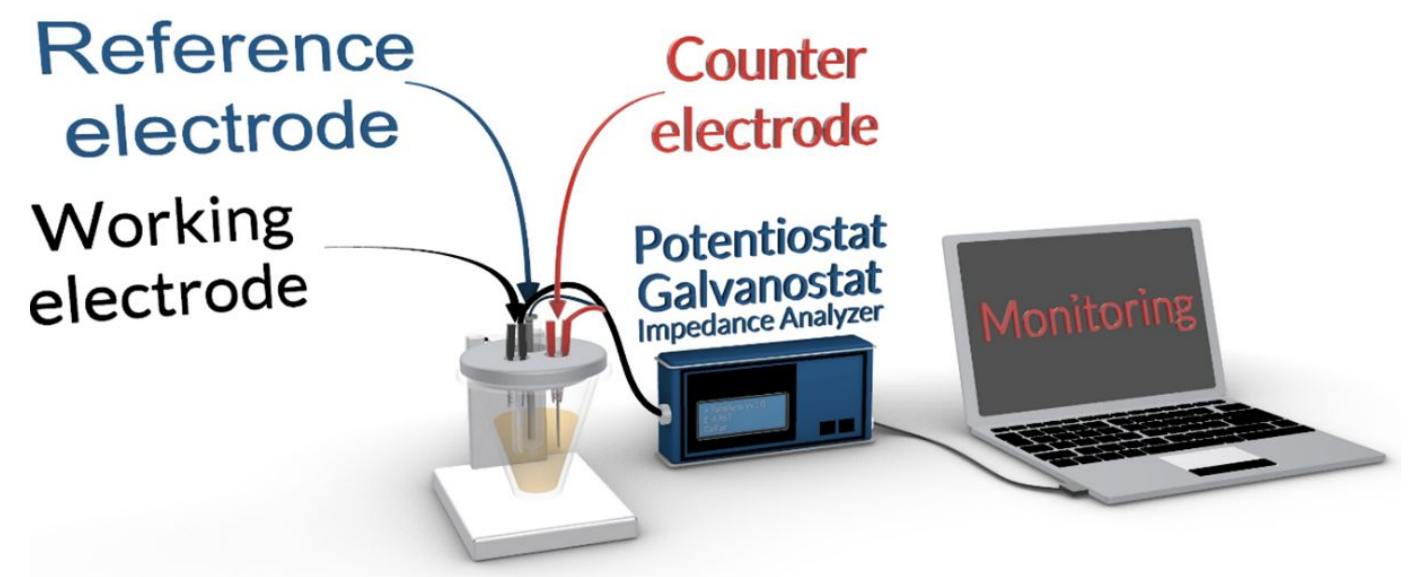

Scheme S1 The set-up for the electrochemical experiment. A three-electrode set-up was used with an $\mathrm{Hg} / \mathrm{HgO}$, a Pt foil, and FTO (GC, Au, or Pt) as the reference, counter, and working electrode, respectively. 


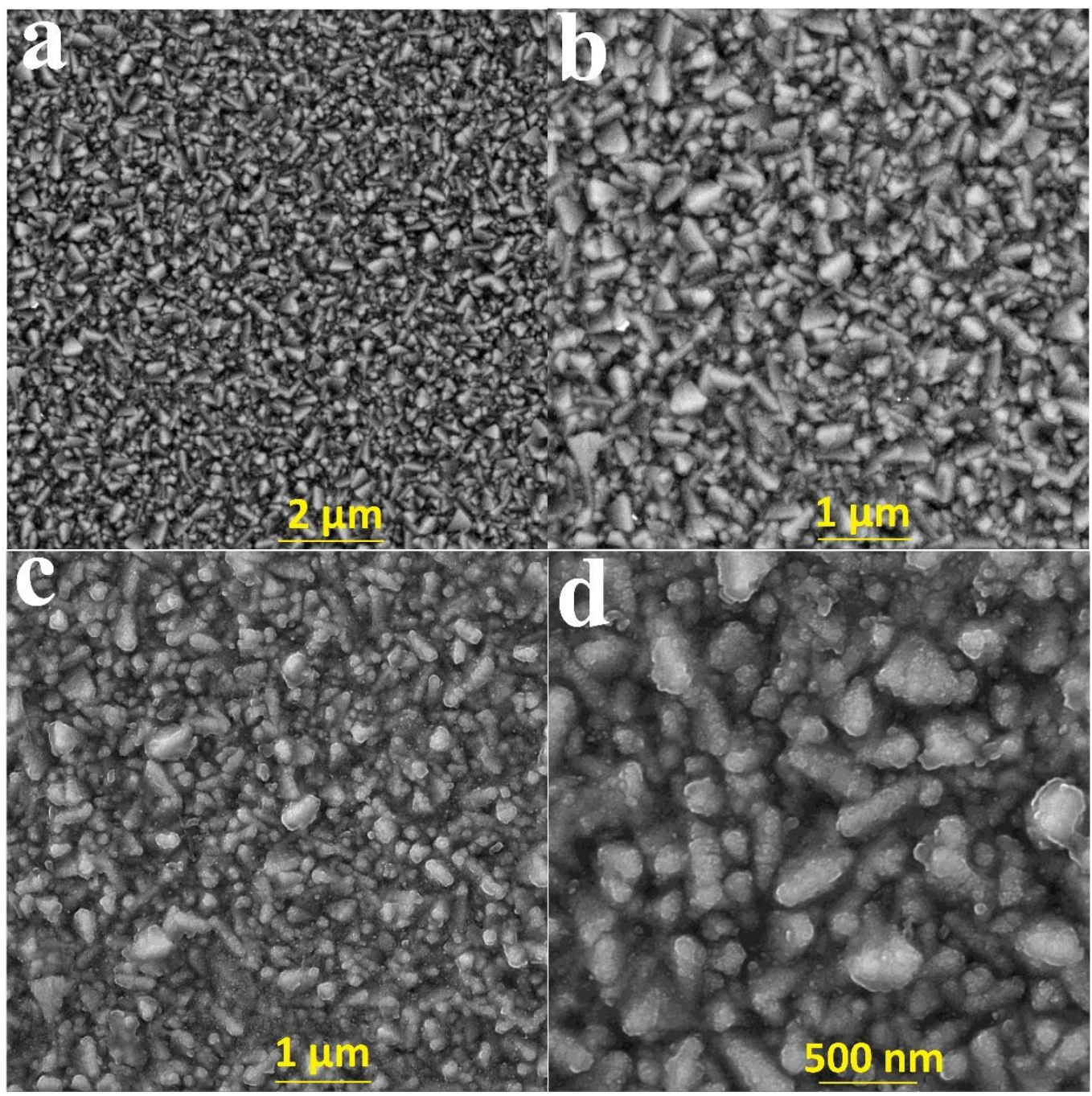

Figure S1 SEM images of a bare FTO electrode at different magnifications (a-d). 

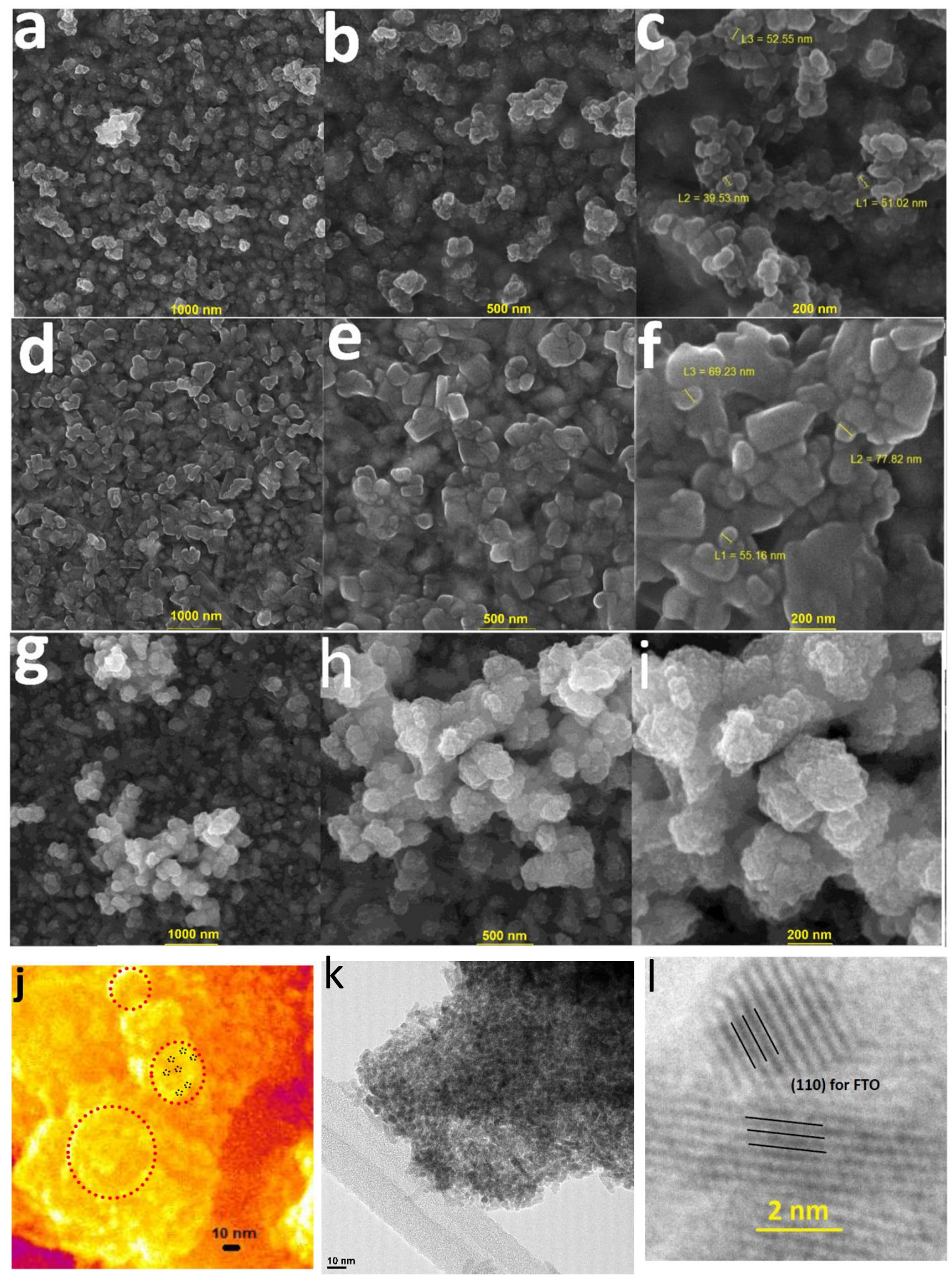

Figure S2 SEM images of an FTO in the presence of $1(1.4 \mathrm{mM})$ under chronoamperometry at $2.36 \mathrm{~V}$ for two (a-c), four ( $(\mathrm{d}-\mathrm{f})$, and 24 hours $(\mathrm{g}-\mathrm{j})$ in a $\mathrm{KOH}$ solution $(1.0 \mathrm{M})$. The red and black circles show big and small nanoparticles $(\mathrm{j})$. TEM (k) and HRTEM (I) images of mechanically separated particles of an FTO in the presence of $1(1.4 \mathrm{mM})$ under chronoamperometry at $2.36 \mathrm{~V}$ for four hours in a $\mathrm{KOH}$ solution $(1.0 \mathrm{M})$. 

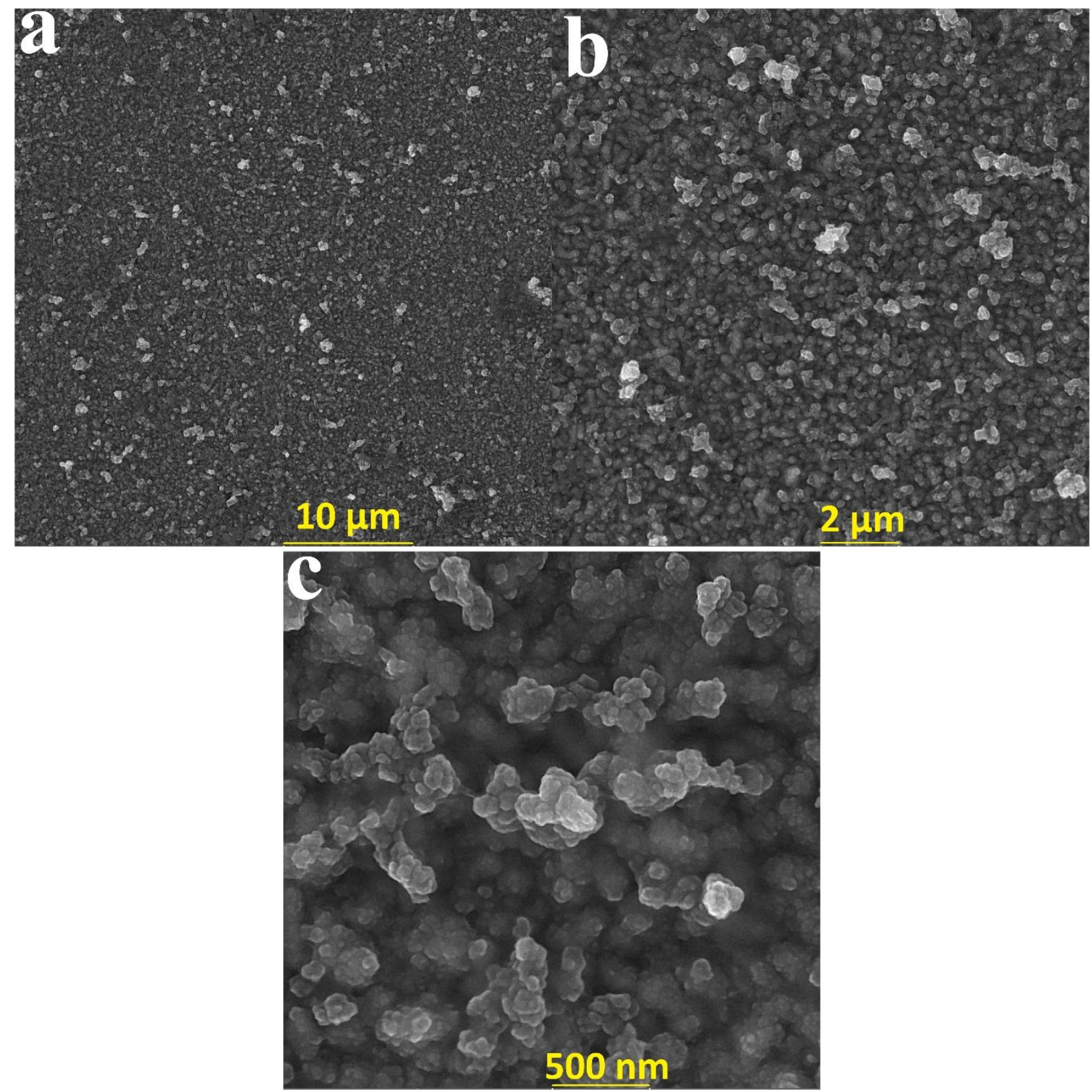

Figure S3 SEM images of an FTO in the presence of $1(1.4 \mathrm{mM})$ under chronoamperometry at $2.36 \mathrm{~V}$ for two hours in the $\mathrm{KOH}$ solution $(1.0 \mathrm{M})$ at different magnifications $(\mathrm{a}-\mathrm{c})$. 

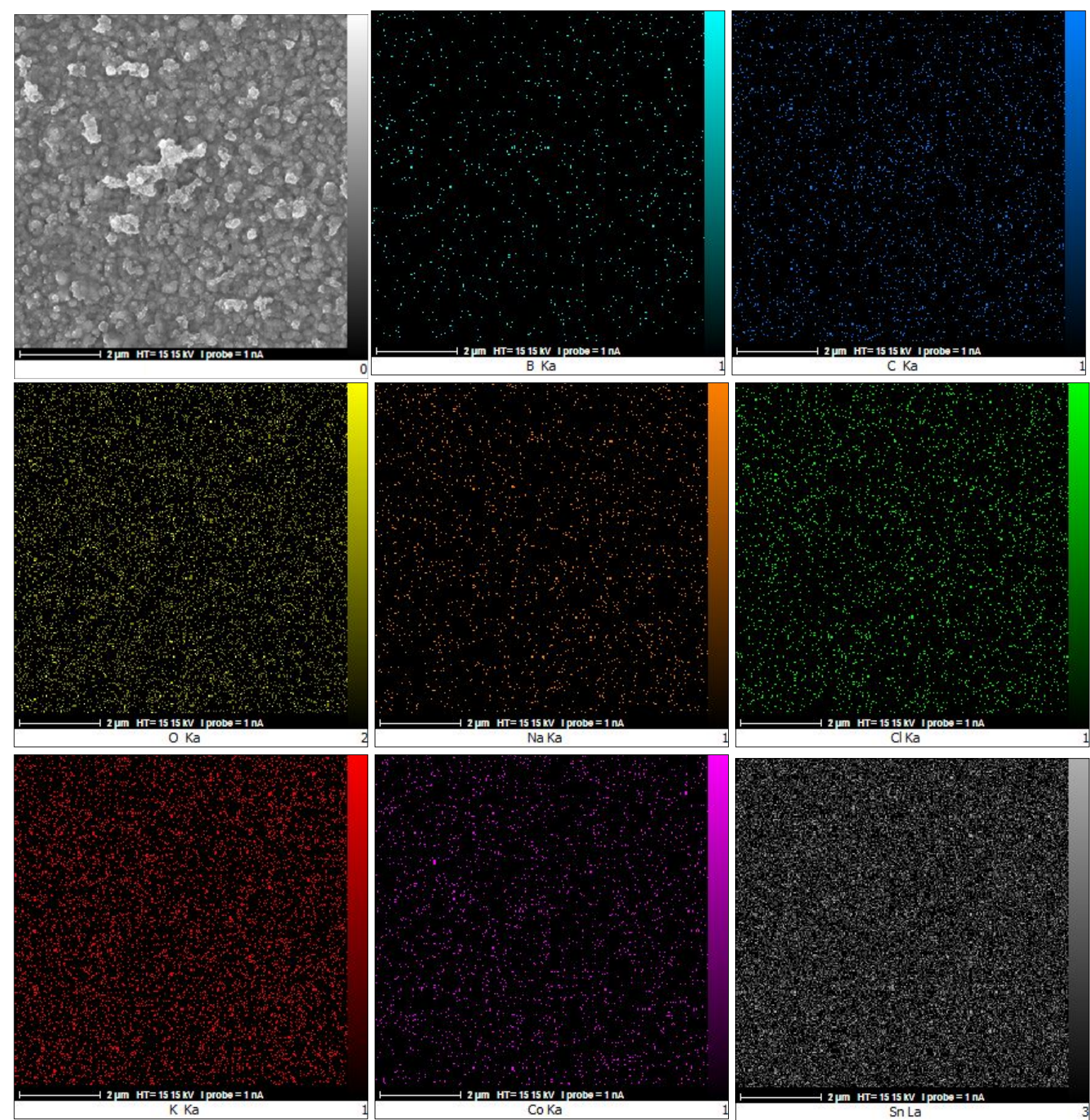

Figure S4 SEM-EDX Mapping images of an FTO in the presence of $\mathbf{1}(1.4 \mathrm{mM})$ under chronoamperometry at $2.36 \mathrm{~V}$ for two hours in the $\mathrm{KOH}$ solution (1.0 M). 

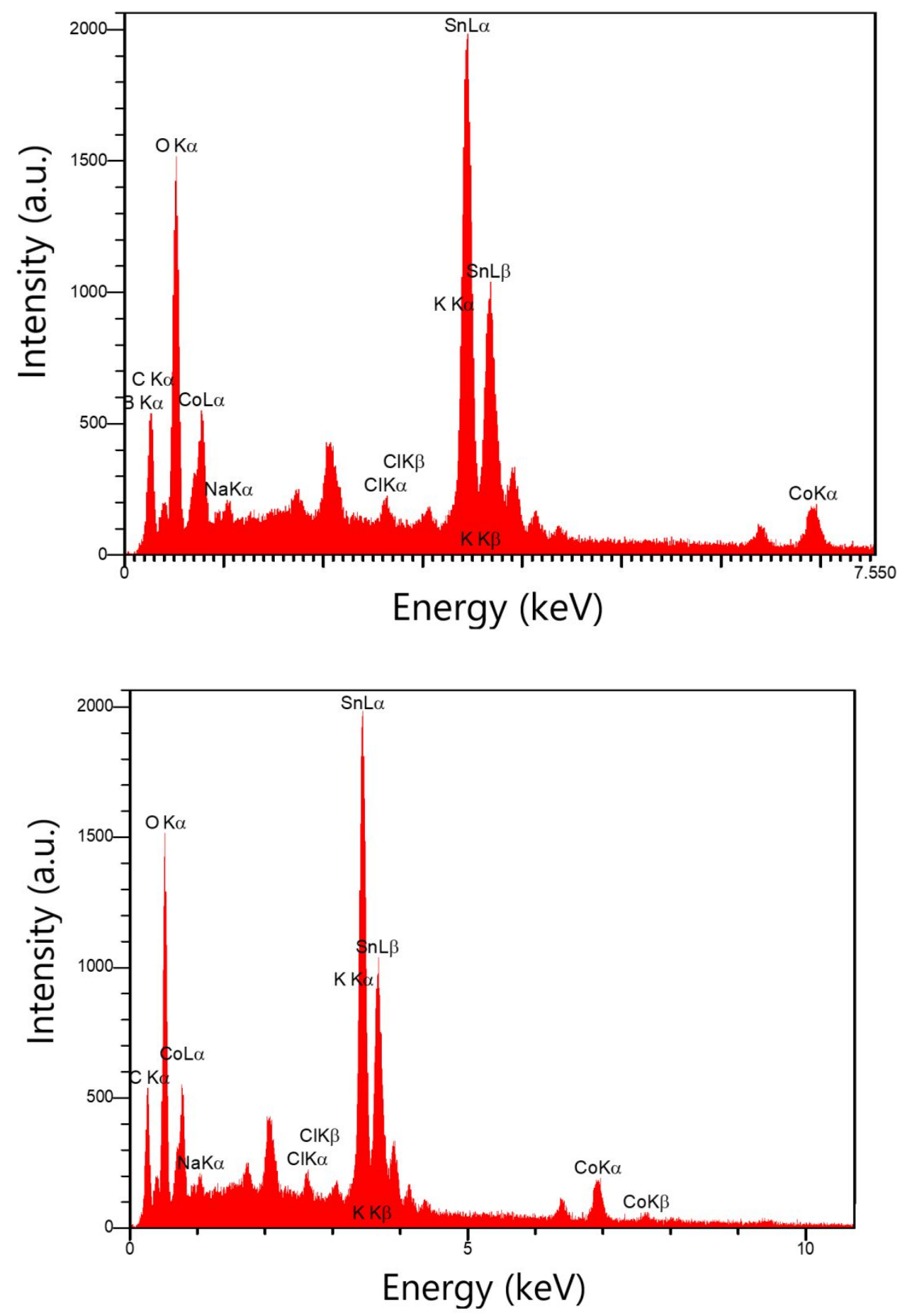

Figure S5 EDX spectra for two areas of an FTO in the presence of $\mathbf{1}(1.4 \mathrm{mM})$ under chronoamperometry at $2.36 \mathrm{~V}$ for two hours in the $\mathrm{KOH}$ solution (1.0 M). 

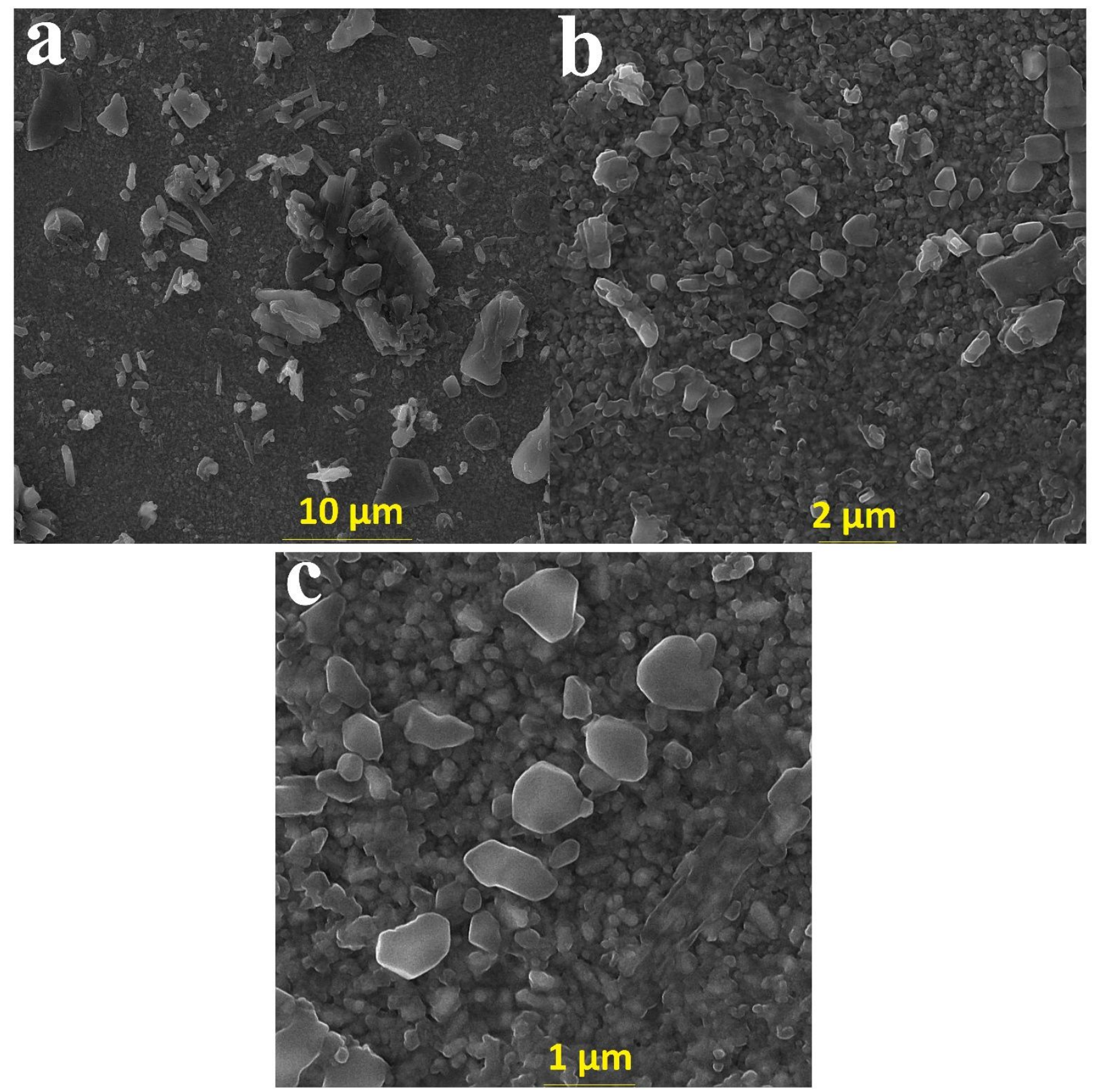

Figure S6 SEM images of an FTO in the presence of $1(1.4 \mathrm{mM})$ under chronoamperometry at $2.36 \mathrm{~V}$ for four hours in the $\mathrm{KOH}$ solution $(1.0 \mathrm{M})$ at different magnifications $(\mathrm{a}-\mathrm{c})$. 

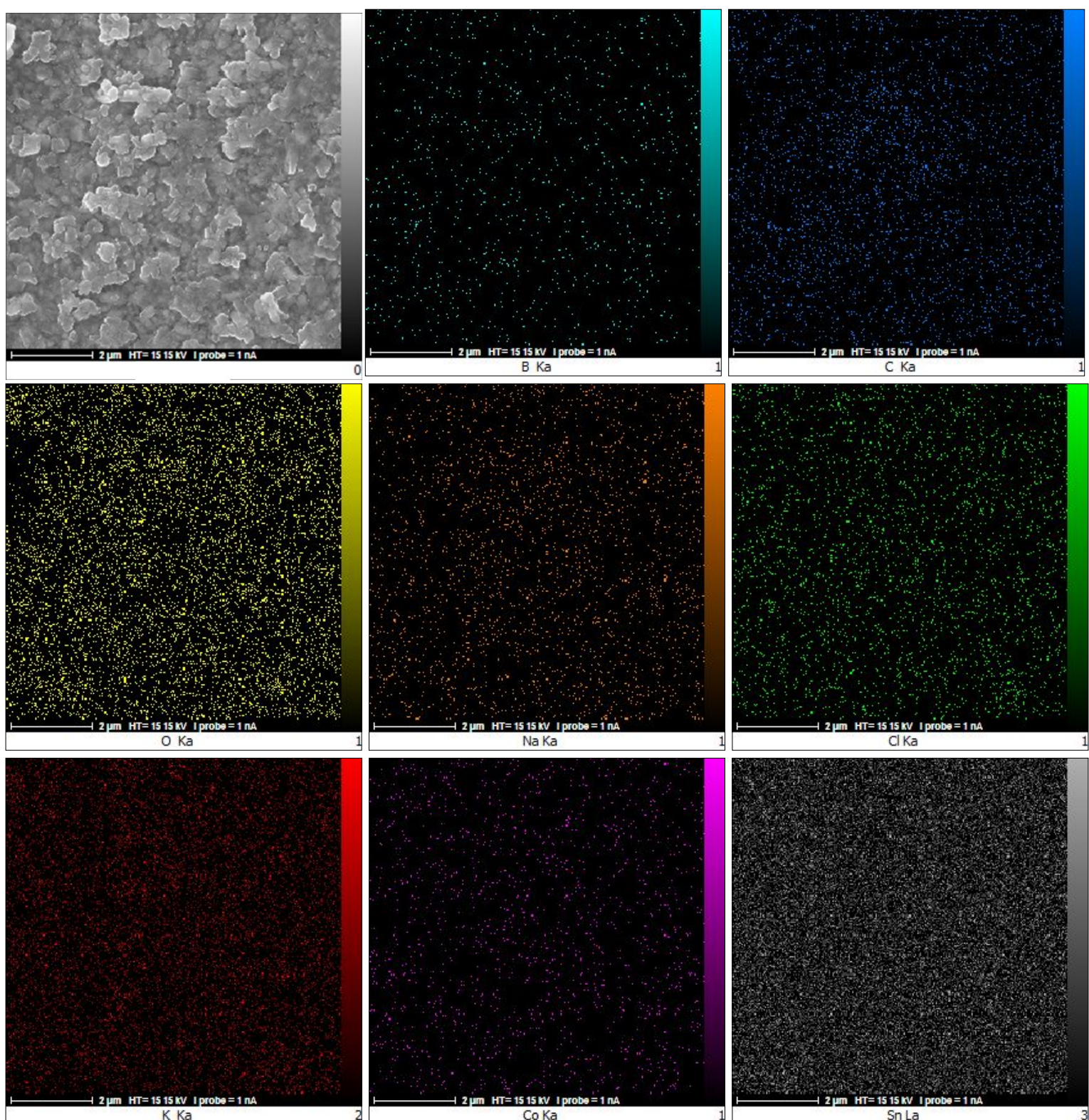

Figure S7 SEM-EDX Mapping images of an FTO in the presence of $1(1.4 \mathrm{mM})$ under chronoamperometry at $2.36 \mathrm{~V}$ for four hours in the $\mathrm{KOH}$ solution $(1.0 \mathrm{M})$. 

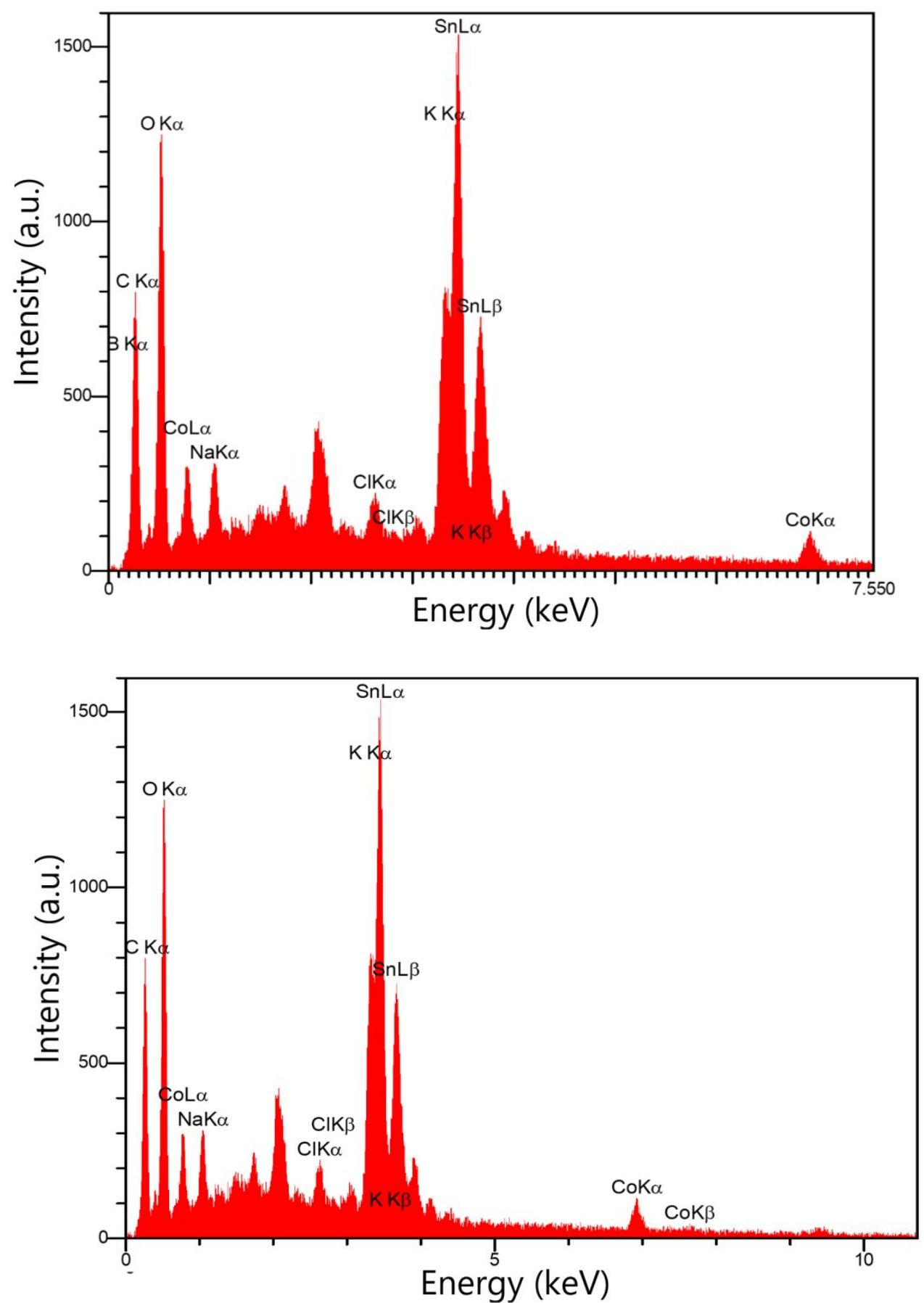

Figure S8 EDX spectra of two areas of an FTO in the presence of $\mathbf{1}(1.4 \mathrm{mM})$ under chronoamperometry at $2.36 \mathrm{~V}$ for four hours in the $\mathrm{KOH}$ solution (1.0 M). 

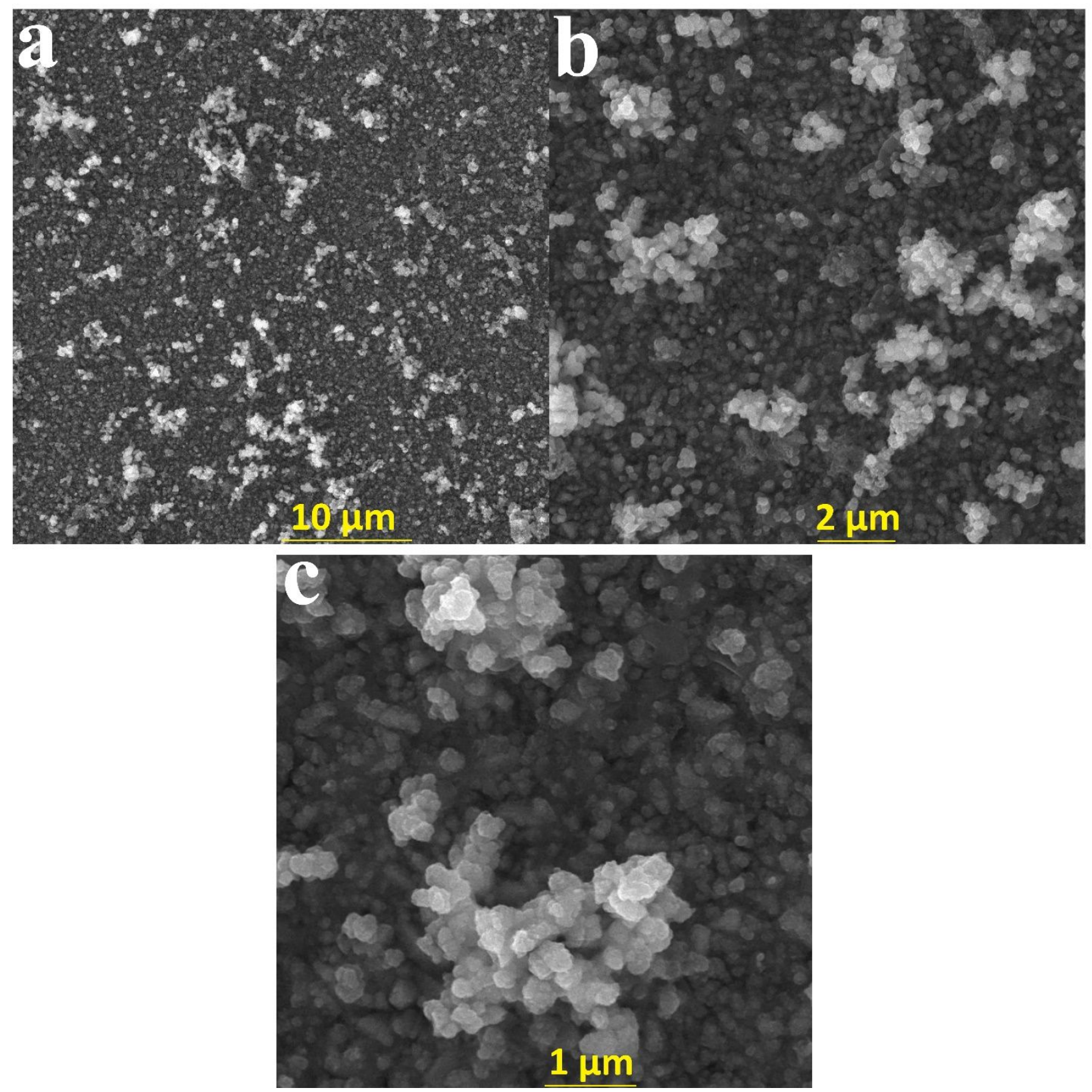

Figure S9 SEM images of an FTO in the presence of $1(1.4 \mathrm{mM})$ under chronoamperometry at $2.36 \mathrm{~V}$ for 24 hours in the $\mathrm{KOH}$ solution $(1.0 \mathrm{M})$ at different magnifications (a-c). 

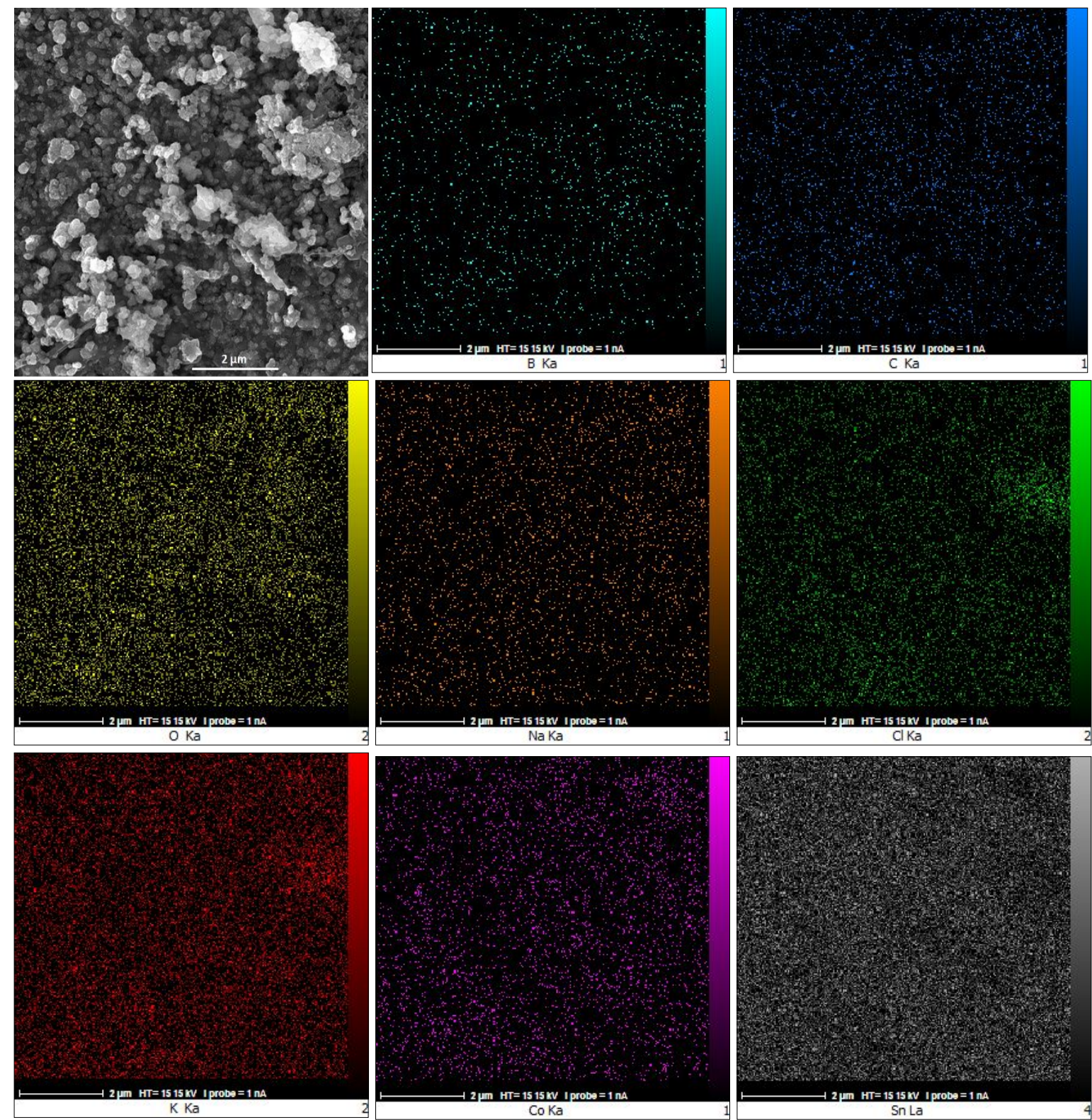

Figure S10 SEM-EDX Mapping images of an FTO in the presence of 1 (1.4 mM) under chronoamperometry at $2.36 \mathrm{~V}$ for 24 hours in the $\mathrm{KOH}$ solution $(1.0 \mathrm{M})$. 


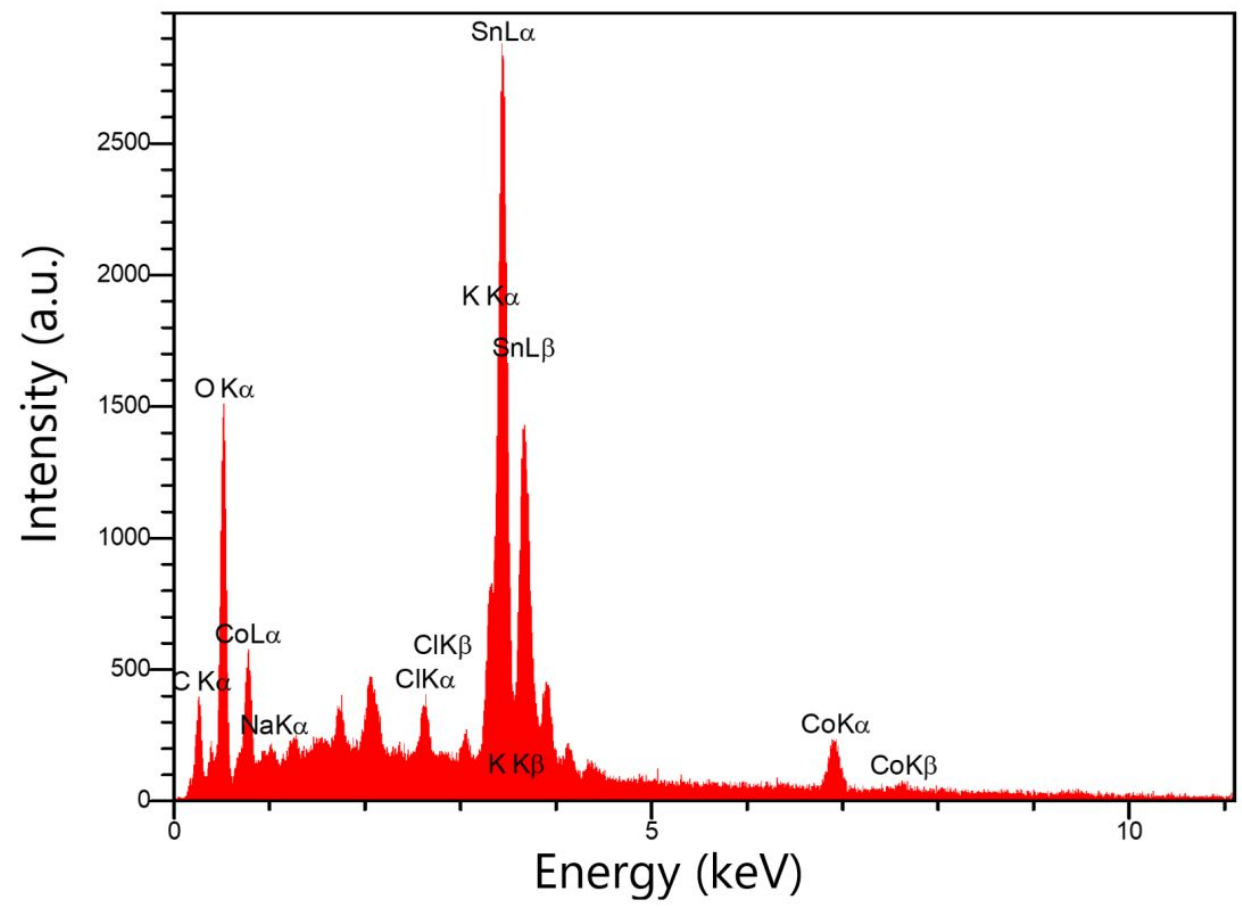

Figure S11 EDX spectra of an FTO in the presence of $1(1.4 \mathrm{mM})$ under chronoamperometry at $2.36 \mathrm{~V}$ for 24 hours in the $\mathrm{KOH}$ solution (1.0 M). 

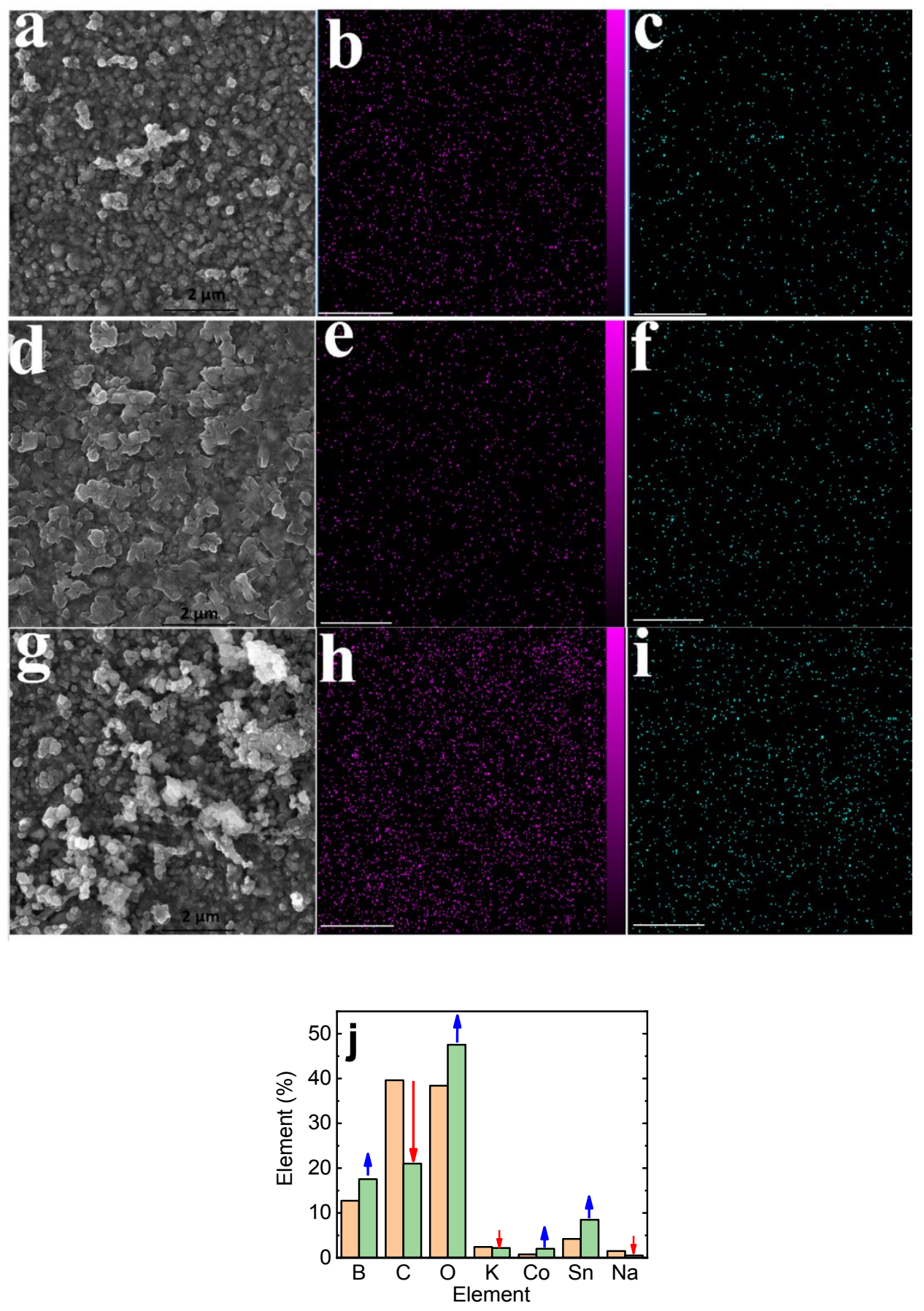

Figure S12 SEM-EDX mapping (Co: purple; B: green) of 1 under the chronoamperometry at $2.36 \mathrm{~V}$ for two (a-c), four $(d-f)$, and 24 hours $(g-i)$ in a $\mathrm{KOH}$ solution $(1.0 \mathrm{M})$. Plot j shows the amounts of the elements on the surface of the electrode after 4 hours (orange) and 24 hours (green). The red and blue arrows show a decrease or increase in elemental content after the operation, respectively. 


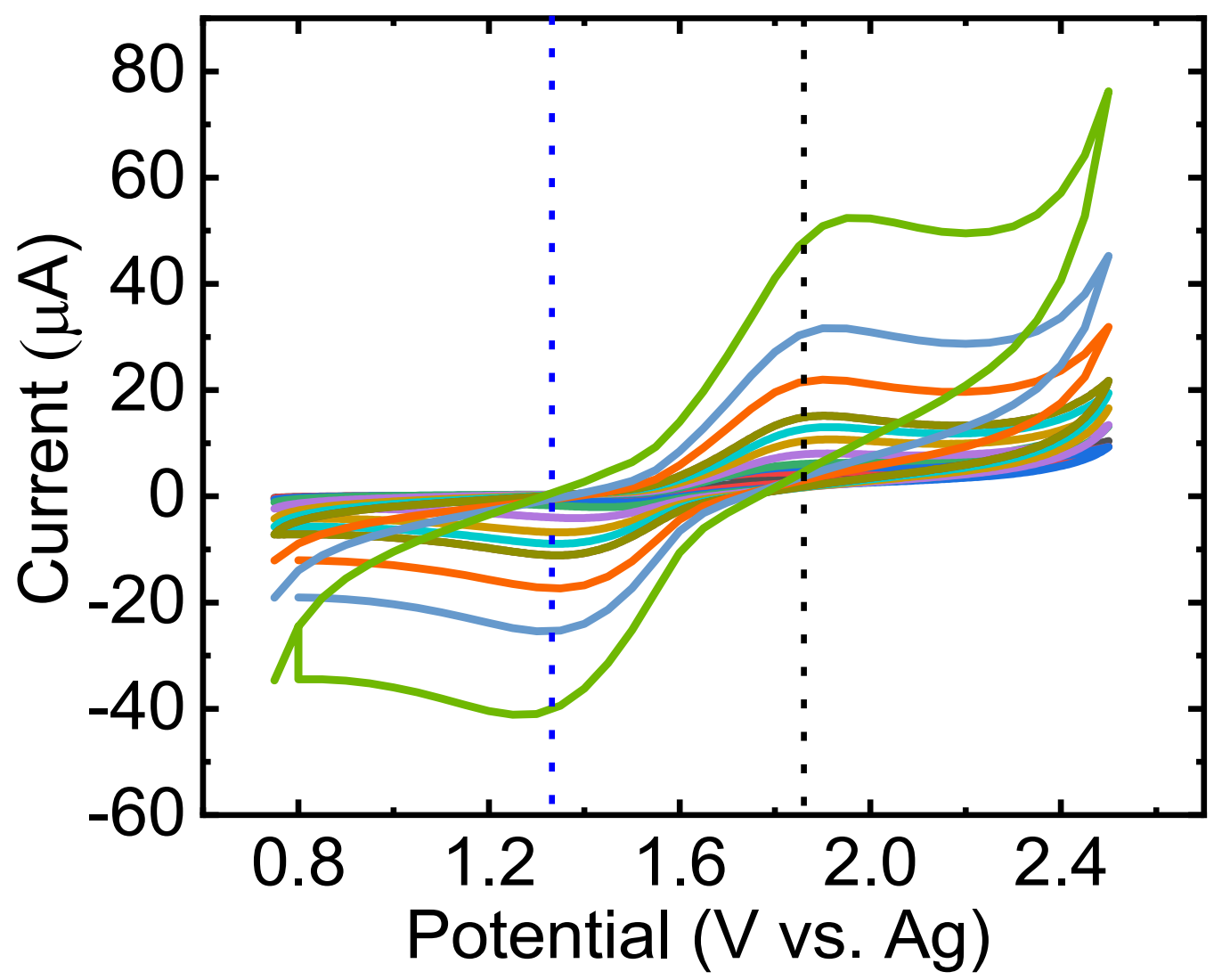

Figure S13 CV with different scan rates $(5,10,25,50,100,200,300,400,500,1000,2000$, and $5000 \mathrm{mV} / \mathrm{s})$ in pure acetonitrile $\left(\mathrm{LiClO}_{4}: 0.25 \mathrm{M}\right)$ in the presence of $1(1.4 \mathrm{mM})$ using FTO. 


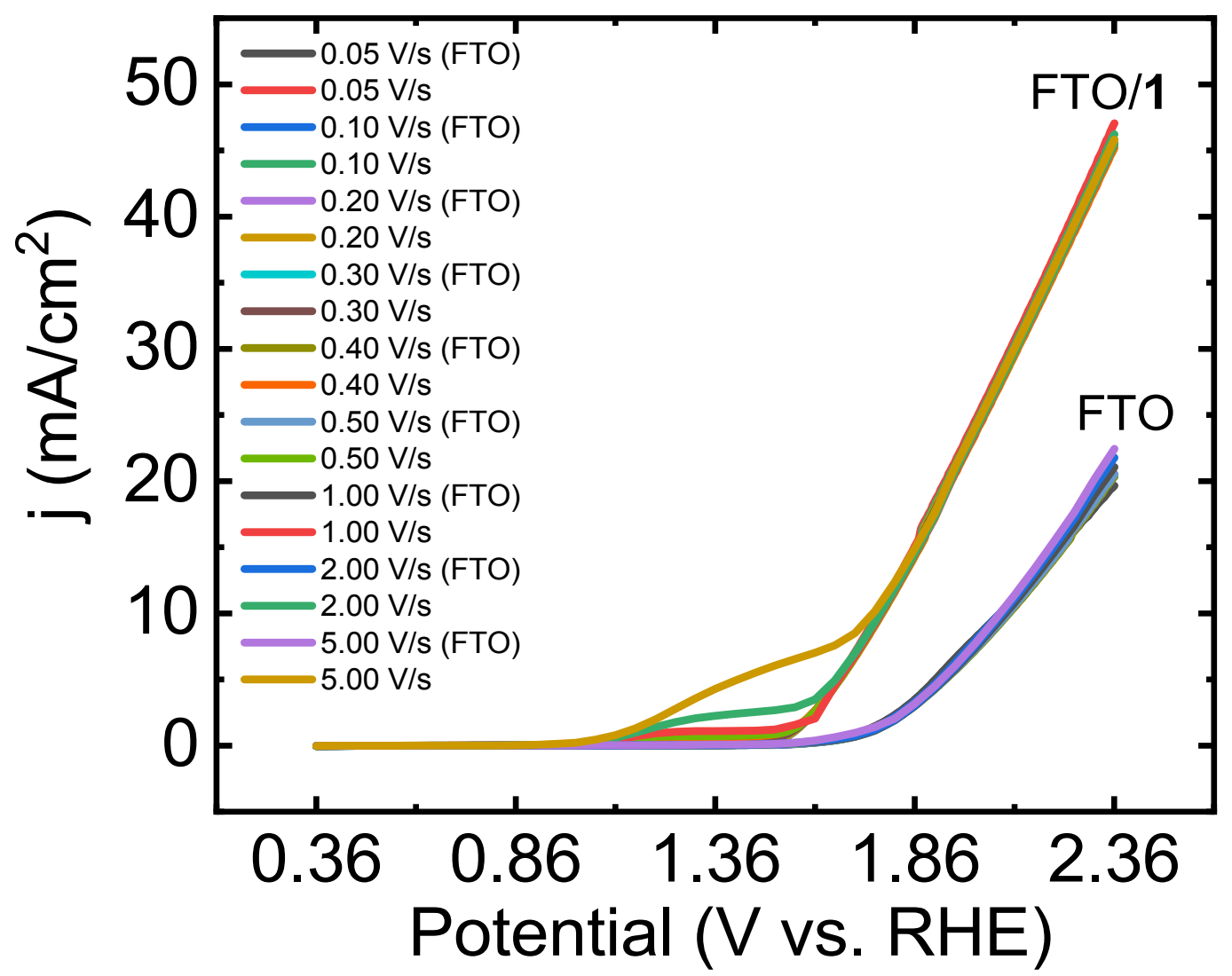

Figure S14 LSVs of an FTO in the absence and presence of $1(1.4 \mathrm{mM})$ in the $\mathrm{KOH}$ solution $(1.0 \mathrm{M})$ at different scan rates. 


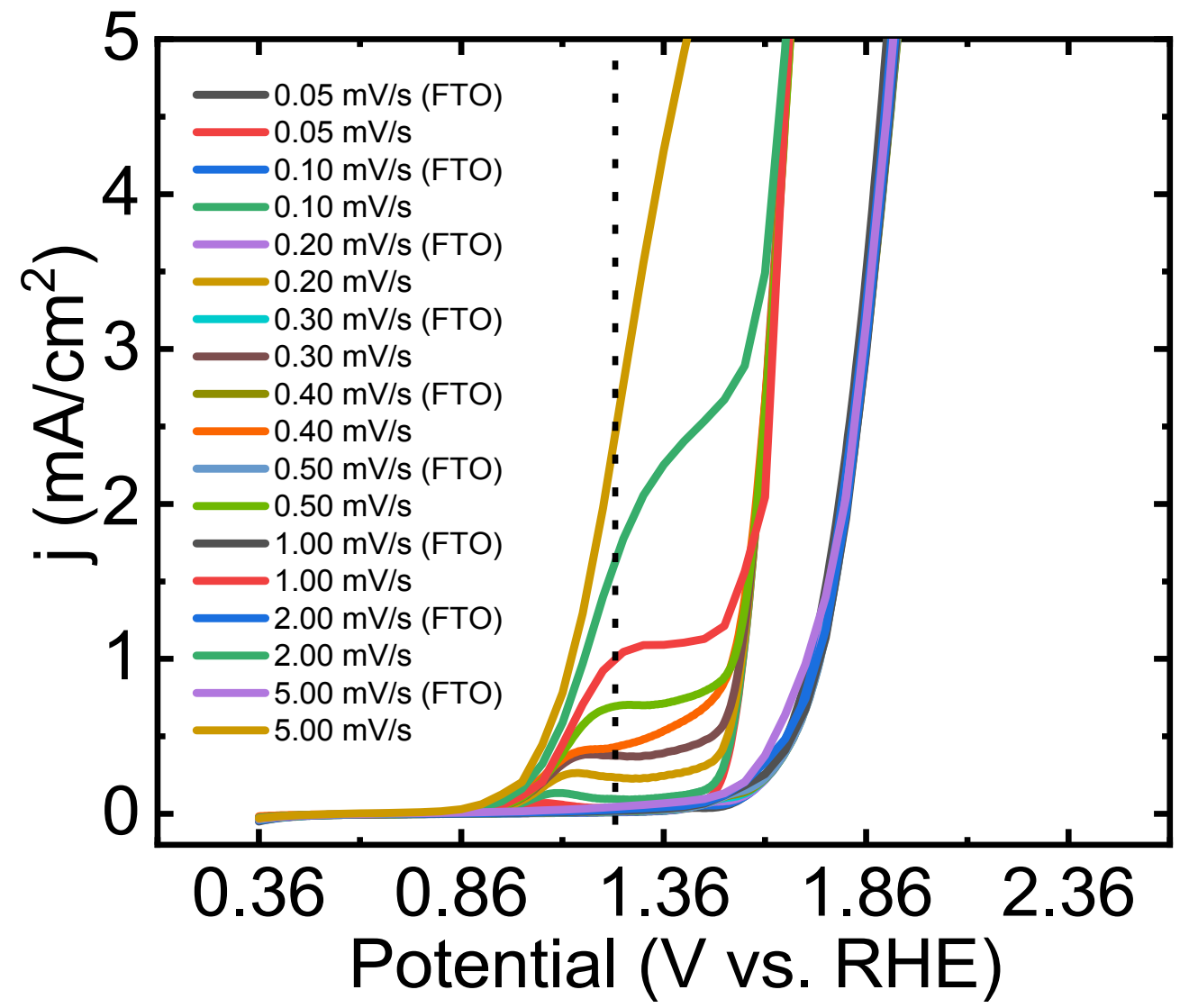

Figure S15 LSVs of an FTO in the presence and the absence of $1(1.4 \mathrm{mM})$ in the $\mathrm{KOH}$ solution $(1.0 \mathrm{M})$ at different scan rates. 

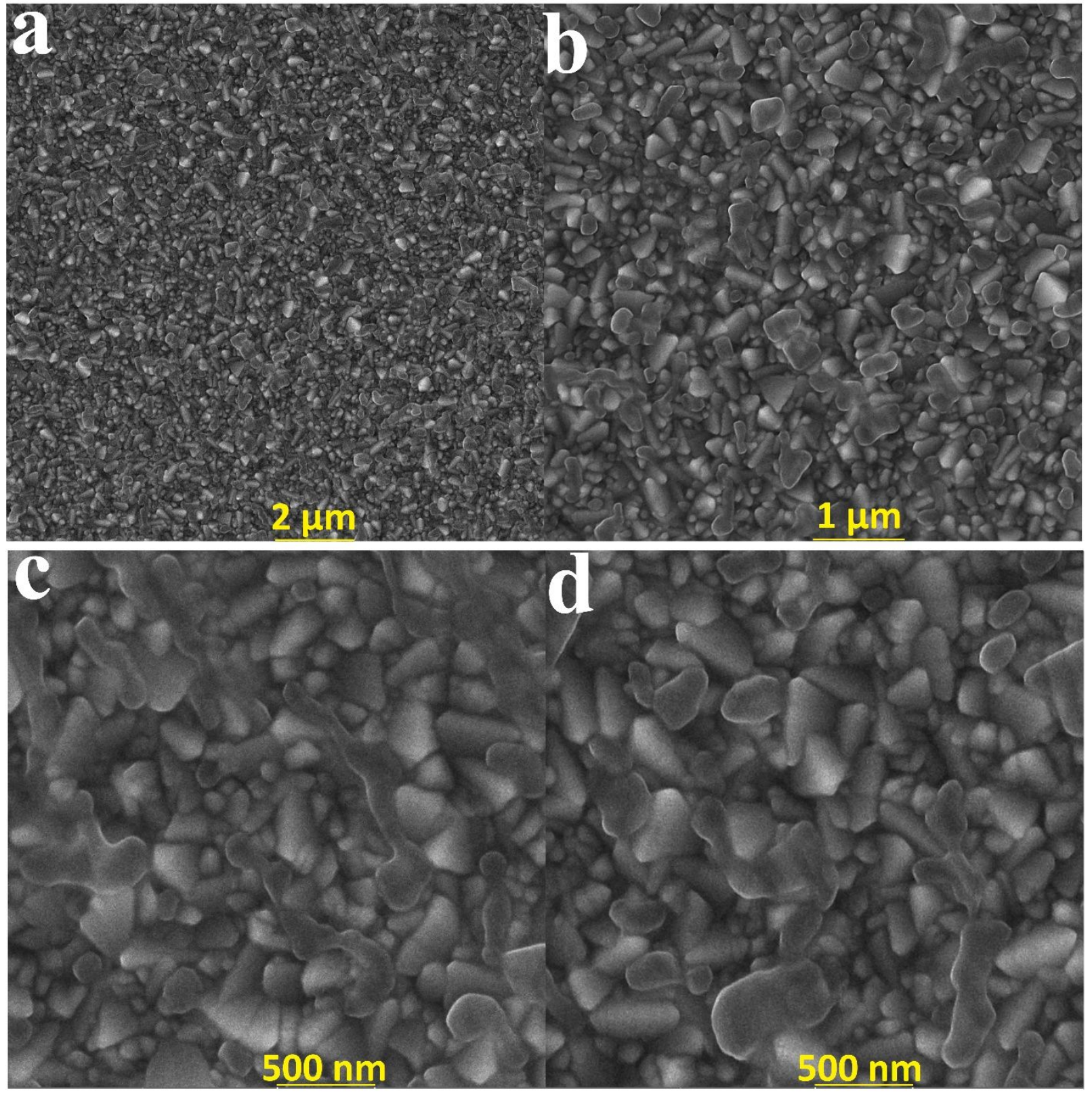

Figure S16 SEM images show no nanosized particle containing cobalt after washing with EDTA at different magnifications (see Figure 5 for details). (a-d). 

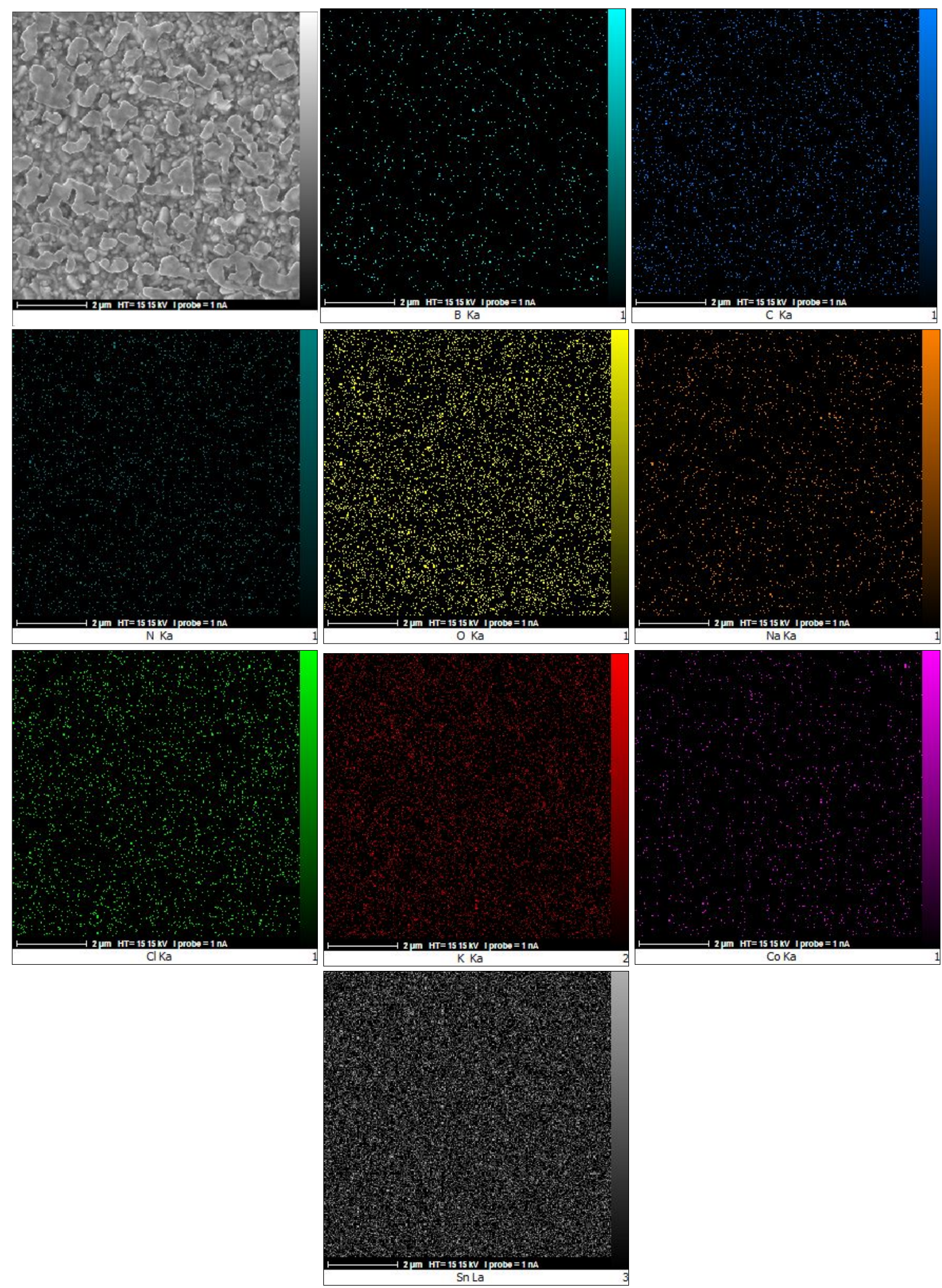

$\mathrm{CoKa}$

SnLa

Figure S17 SEM-EDX mapping shows no nanosized particle containing cobalt after washing with EDTA (see Figure 5 for details). 

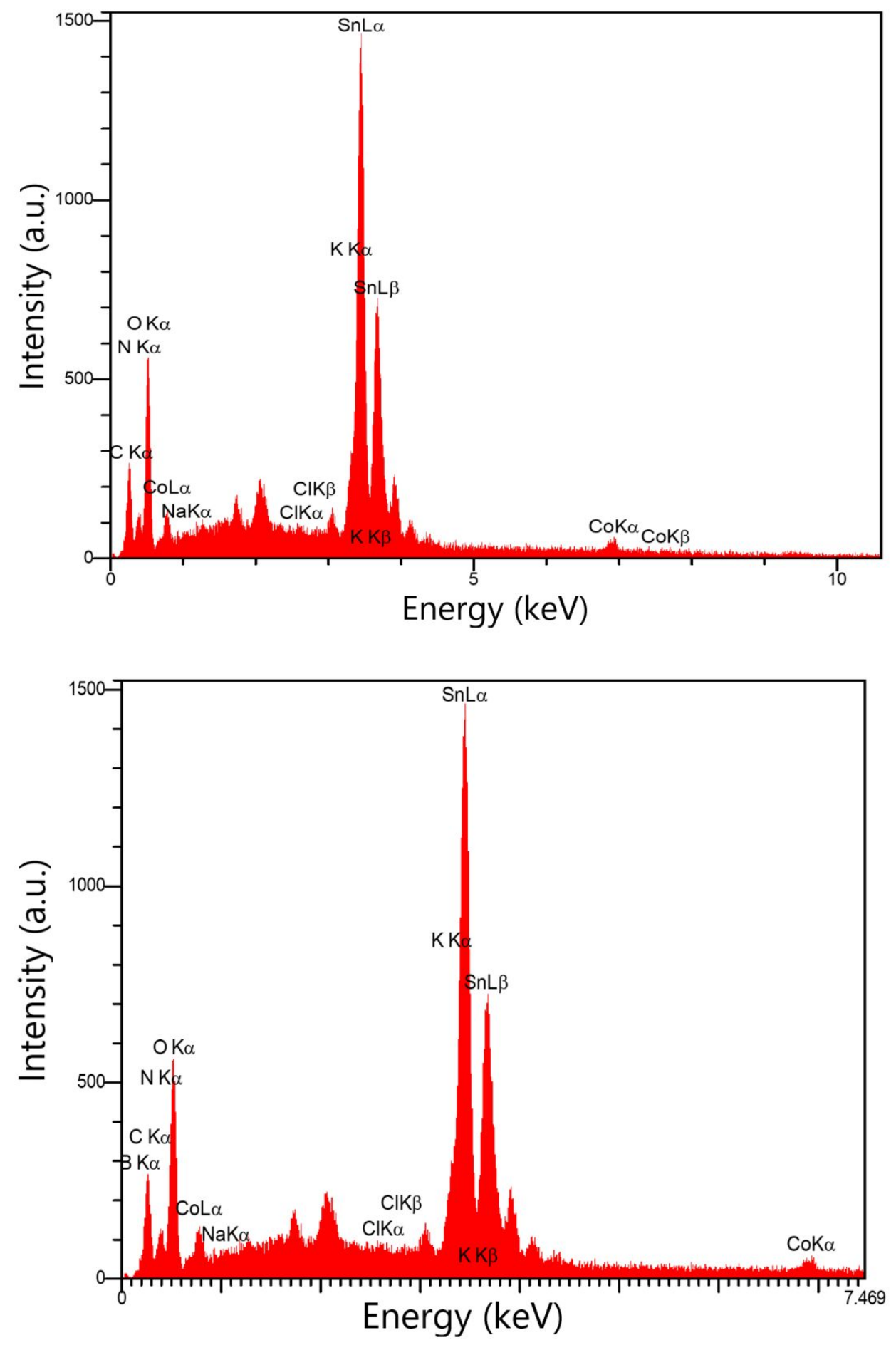

Figure S18 EDX spectra for two areas of the operated FTO show no nanosized particle containing cobalt after washing with EDTA (see Figure 5 for details). 


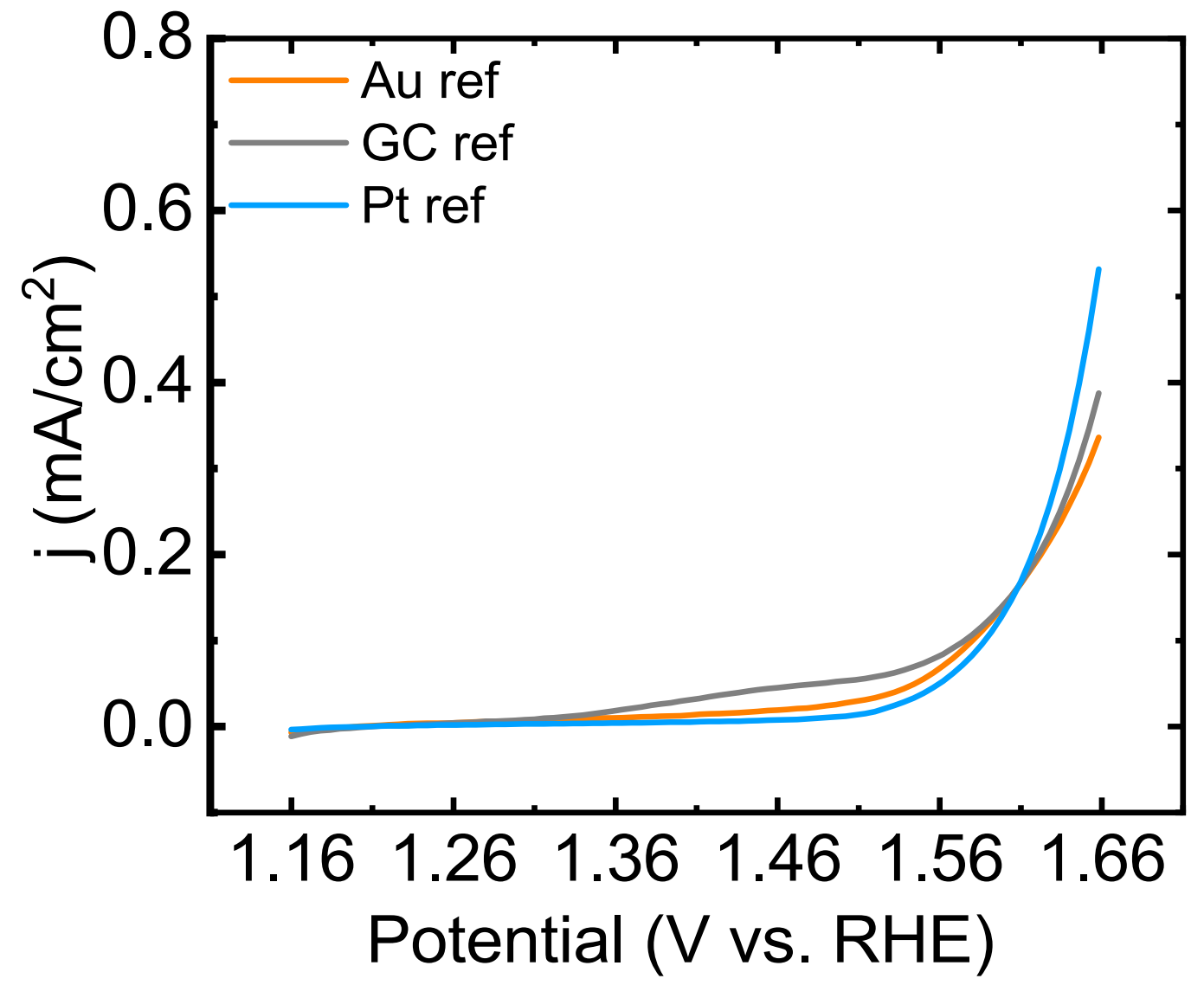

Figure. S19 LSVs of Pt (blue), Au (orange), and GC (gray) in the presence of $\mathrm{KOH}(1.0 \mathrm{M})$ and in the absence of 1 at a scan rate of $10 \mathrm{mV} / \mathrm{s}$. 


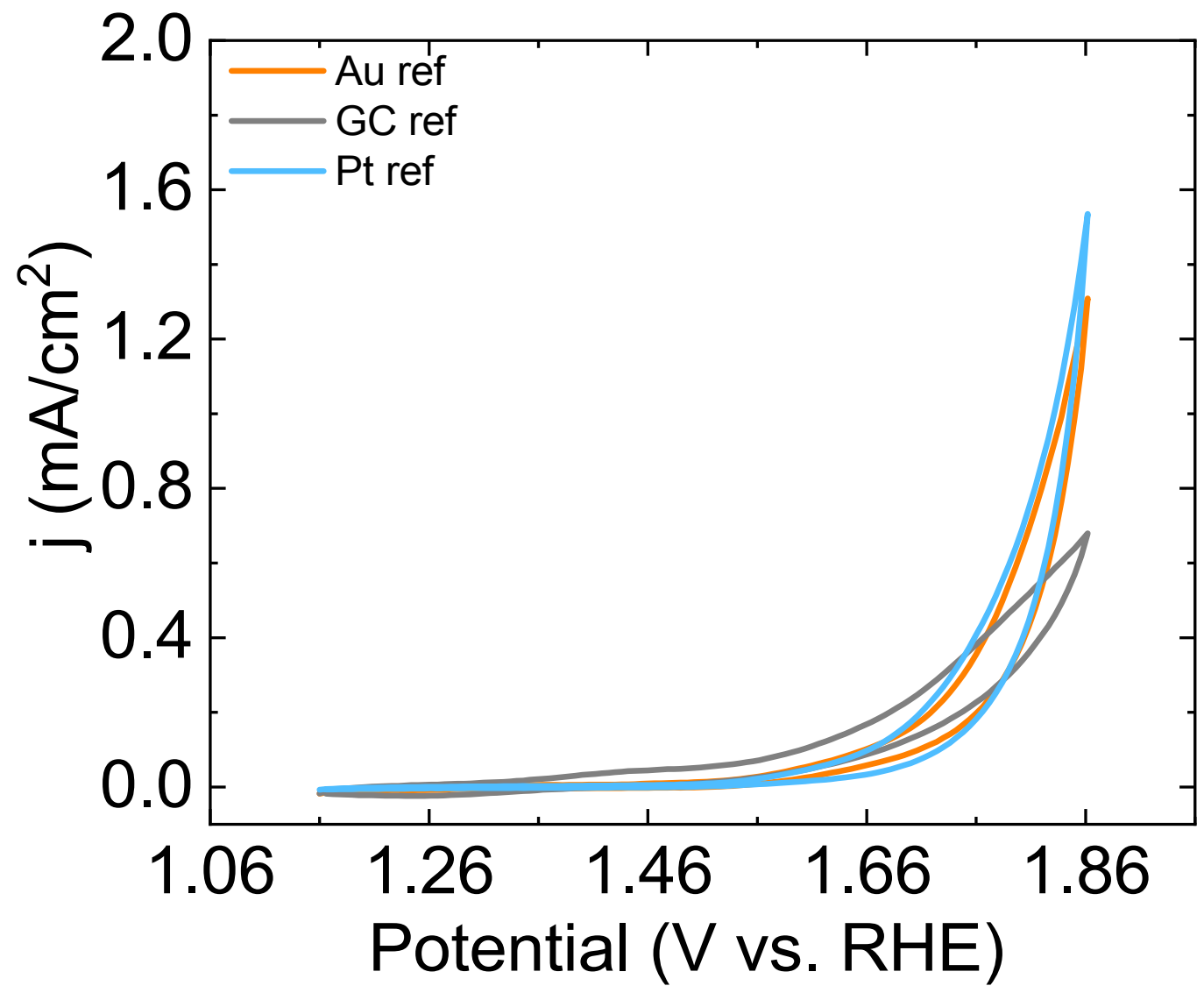

Figure S20 CVs of Pt (blue), Au (orange), and GC (gray) in the presence of $\mathrm{KOH}(1.0 \mathrm{M})$ and in the absence of 1. 


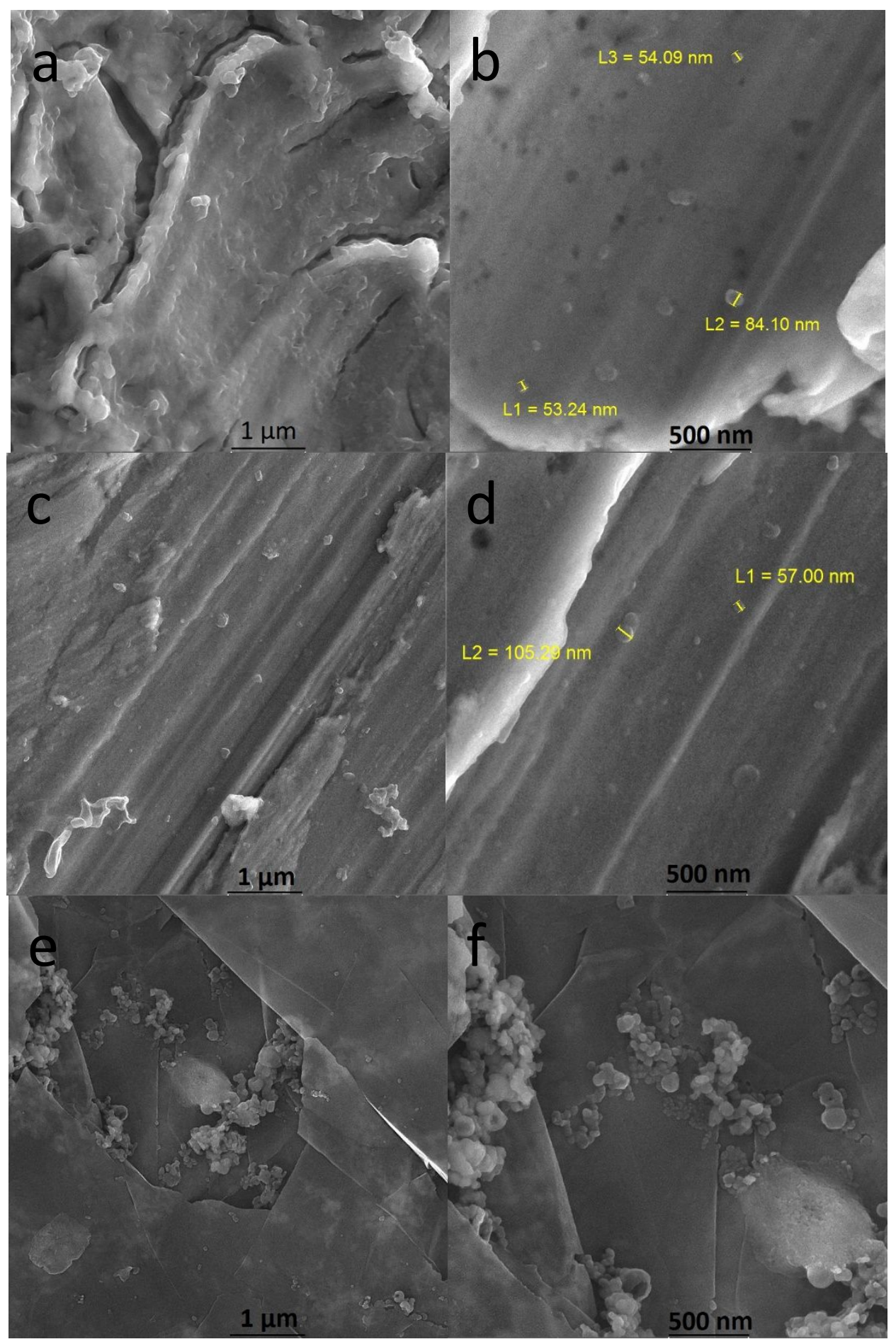

Figure S21 SEM images of an FTO in the presence of $1(1.4 \mathrm{mM})$ under chronoamperometry at $2.36 \mathrm{~V}$ for two hours in the $\mathrm{KOH}$ solution (1.0 M) at different magnifications for $\mathrm{Au}(\mathrm{a}$ and $\mathrm{b})$, Pt ( $\mathrm{c}$ and d), and $\mathrm{C}$ (e and f) as working electrode. 


\section{Reference}

1. Singh, J. P.; Won, S. O.; Lim, W. C.; Lee, I. J.; Chae, K. H. Electronic Structure Studies of Chemically Synthesized $\mathrm{MgFe}_{2} \mathrm{O}_{4}$ Nanoparticles. J. Mol. Struct., 2016, 1108, 444-450. 